\title{
Impact Crashworthiness of a Floating Offshore Nuclear Power Plant Hull Structure in a Terrorist Attack with an Aircraft Strike
}

\author{
Jeom Kee Paik ${ }^{\mathrm{a}, \mathrm{b}, \mathrm{c}^{*}}$ and Jae Hyeong Park ${ }^{\mathrm{b}}$ \\ ${ }^{a}$ The International Centre for Advanced Safety Studies / Korea Ship and Offshore \\ Research Institute (The Lloyd's Register Foundation Research Centre of Excellence), \\ Pusan National University, Busan, South Korea \\ b Department of Naval Architecture and Ocean Engineering, Pusan National \\ University, Busan, South Korea \\ ${ }^{\mathrm{c}}$ Department of Mechanical Engineering, University College London, London, UK \\ * Corresponding author. J.K. Paik. (Email) j.paik@ucl.ac.uk
}

\begin{abstract}
The aim of this study is to investigate the impact crashworthiness of a floating offshore nuclear power plant hull structure in an aircraft strike; the hull has a double-sided design that includes ballasting with either sand or concrete. As a hazardous event associated with a terrorist attack, one of the unfavourable impact scenarios is adopted in which a Boeing 777 airplane strikes the hull structure at a full speed. This study examines the contribution of ballasting materials such as sand or concrete to the penetration of the striking body into the hull structure in an aircraft strike as the power plant is gravity based sitting on the seabed. The LS-DYNA nonlinear finite-element method is employed for the structural crashworthiness analysis. Details of the computational modelling and resulting insights are documented.
\end{abstract}

Keywords: Floating nuclear power plant, Aircraft strike, Structural crashworthiness, Terrorist attack, Nonlinear finite-element method

\section{Introduction}

A floating nuclear power plant is a non-self-propelled vessel that generates electrical power with one or more nuclear reactors installed inside a vessel at sea. It offers many advantages because it can provide electricity and heat to remote, relatively inaccessible sites. The plant can be built at a shipyard and towed to the site of operation, which makes it unnecessary to set up a special site for its construction. Viability studies on land and the land environment are not needed because the environmental impact at sea is low for both operation and dismantling, although it must of course be ensured that radioactive material is never leaked to the sea.

The first floating nuclear power plant was reportedly MH-1A, which was built in the 1960s into the hull of a World War II Liberty Ship in association with the U.S. Army Nuclear Power Program, which sought to develop small nuclear reactors to generate electrical and space-heating energy (Adams 1995). A Russian floating nuclear power plant was recently launched to operate in the Chukotka district in northwestern Russia, containing two reactors each with 35-MWe capacity mounted on 
a $144 \times 30-\mathrm{m}$ vessel, as shown in Figure 1 (Foro Nuclear 2019). China General Nuclear Power Group (CGN) also plans to launch a floating nuclear power plant to generate electricity using a small modular multifunction floating reactor with a 100-MWe capacity by 2020, as shown in Figure 2. Massachusetts Institute of Technology (MIT) is developing a floating nuclear power plant for two versions of a cylindrical platform design, as shown in Figure 3. The smaller version has a diameter of $45 \mathrm{~m}$ and produces $300 \mathrm{MW}$ of electricity, and the larger version has a diameter of $75 \mathrm{~m}$ and can generate up to $1100 \mathrm{MW}$ of electricity (Foro Nuclear 2019).

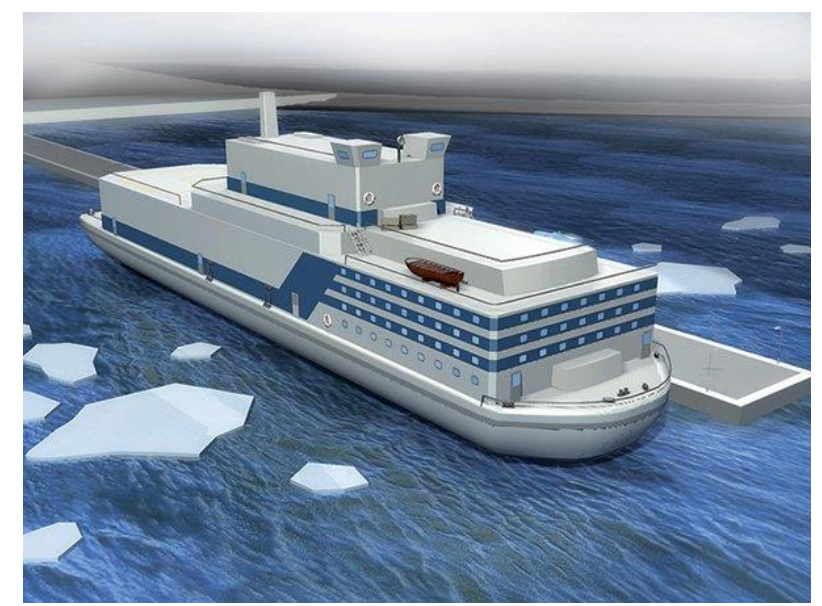

Figure 1. Artist's rendering of the Russian floating nuclear power plant. @ Rosatom.

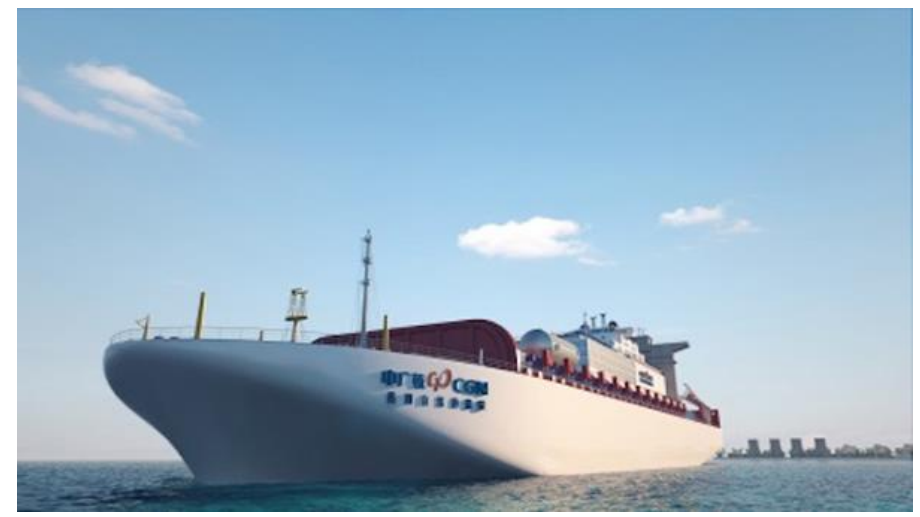

Figure 2. Artist's rendering of CGN's floating nuclear power plant. C CGN.

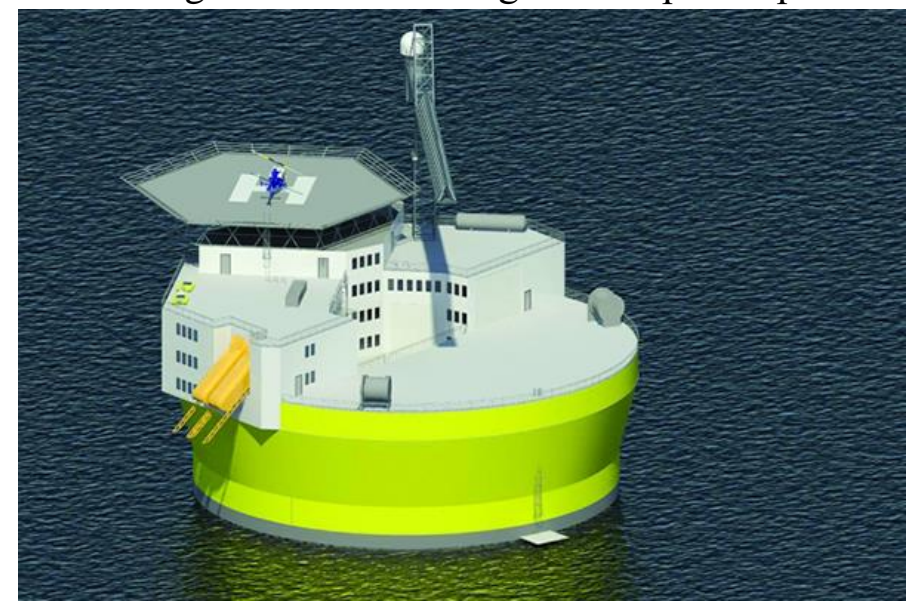

Figure 3. Artist's rendering of MIT's floating nuclear power plant. C) MIT. 


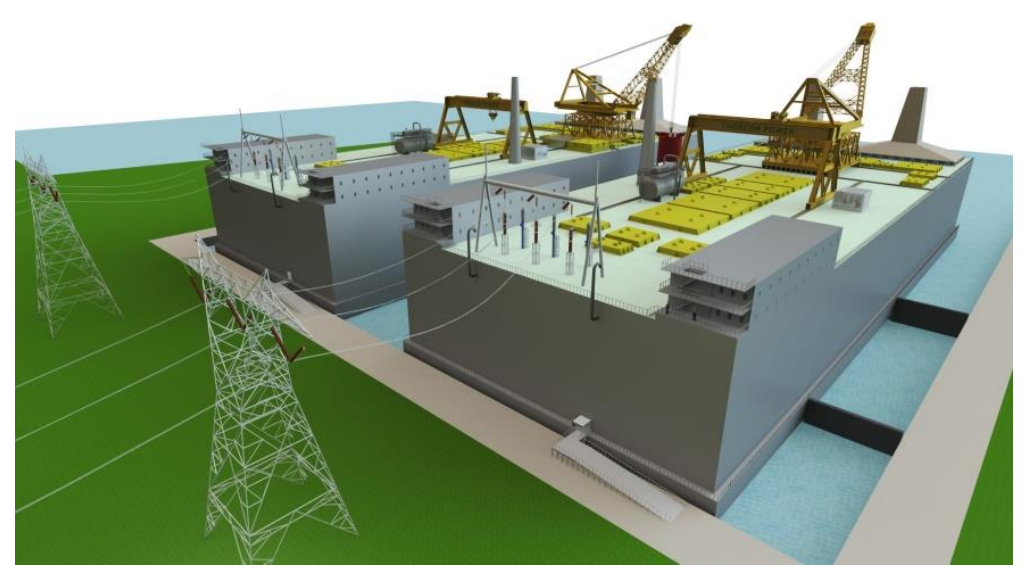

Figure 4. Artist's rendering of ThorCon's floating nuclear power plant. () ThorCon.

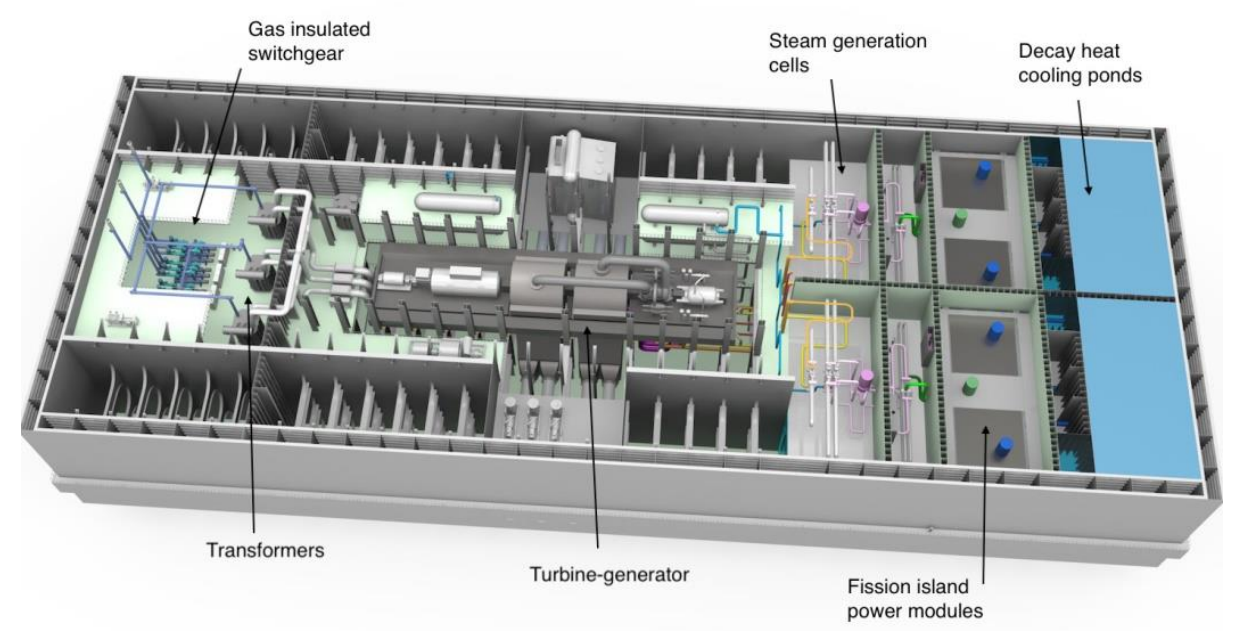

Figure 5. Inside overview of ThorConIsle. (C) ThorCon.

As shown in Figure 4, ThorCon (www.thorconpower.com) has developed a low-pressure, high-temperature, hull-mounted, liquid-fuel nuclear power plant that uses a molten salt fission reactor, known as ThorConIsle. In contrast to all current nuclear reactors, the liquid fuel of ThorConIsle consists of a mixture of low enriched uranium and thorium in a fluoride salt, which greatly enhances the safety associated with accidents because the fuel can be removed with a pump and passively drained in the event of an emergency. The operating pressure of ThorCon's nuclear reactor is the same as a garden hose, whereas standard nuclear reactors operate at as much as 160 bar (or 2300 psi). As shown in Figure 5, each ThorCon plant is based on one or more hulls; each contains two 250-MWe power modules, a 500-MW supercritical turbo generator, gas insulated switchgear, a decay heat pond, and auxiliaries.

The lifespan of the reactors on floating nuclear power plants is more than 40 years. Every 10 to 15 years, the entire floating plant must be towed back to the wharf at which it was constructed for disposal of nuclear waste and necessary maintenance. Therefore, radiation releases are virtually unexpected at the site of operation at sea. 
However, one concern is that floating nuclear power plants may be more vulnerable to accidents and terrorism than land-based nuclear power plants.

Studies on impact crashworthiness of structures struck by an airplane are available to the public. In 1988, Sandia National Laboratories (SNL) in USA performed an F4 Phantom aircraft impact test with an essentially rigid, reinforced concrete target (https://www.youtube.com/watch?v=CZ8uvQk1H9I), as shown in Figure 6 (Sugano et al. 1993). Itoh et al. (2005) performed numerical simulations of the F4 Phantom test using nonlinear finite-element method. The aircraft in the SNL test was accelerated on a $600 \mathrm{~m}$ long two-rail rocket rail and reached a maximum velocity of $215 \mathrm{~m} / \mathrm{s}$. Wierzbicki et al. (2002) and Wierzbicki and Teng (2003) used an analytical method to solve the problem of the airplane wing cutting through the exterior columns of the World Trade Center which are thin-walled box beam made of high strength steel. The problem was modeled as an impact of a rigid mass traveling with a velocity of 240 $\mathrm{m} / \mathrm{s}$ into a hollow box-like vertical member. It was found that the critical impact velocity to fracture the impacted structure was $155 \mathrm{~m} / \mathrm{s}$, indicating that the wing of an airplane can easily cut through the outer column, and the energy absorbed by plastic deformation and fracture of the column is only $6.7 \%$ of the initial kinetic energy.

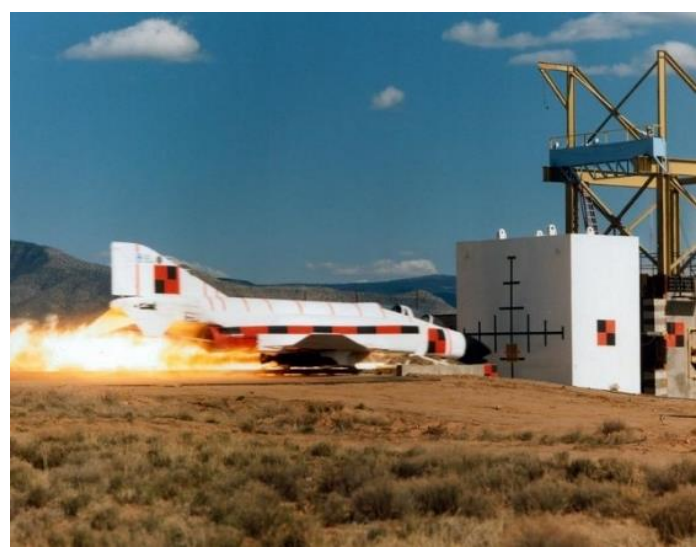

Figure 6. The impact test between a F4 Phantom and a concrete wall (Sugano et al. 1993).

In the present study of a floating nuclear power plant designed by ThorCon (Paik 2019a), the structural crashworthiness of ThorConIsle's hull structure was investigated in a terrorist-attack scenario involving a Boeing 777 airplane and depending on different ballast materials in the double sides, which are used to deploy to the sea bed, where the safety of important equipment should be secured.

\section{ThorCon's Floating Nuclear Power Plant Hull Structures}

ThorConIsle's hull structure is similar to that of a large, longitudinally framed double-hull tanker. The hull has a double bottom and double sides. For most of the hull, the central working portion is flanked by ballast tanks. On deck, ThorConIsle is a bit like a bulk carrier in that it includes several large hatches to allow access for extraction and replacement of various components. However, ThorConIsle is a gravity 
platform. It will be towed to a site in shallow water (about $10 \mathrm{~m}$ ) and ballasted down onto the seabed. The double sides and double bottom will then be filled with sand except in the fission island, in which the double sides will be filled with concrete. In the fission island, the main deck is also a double-skinned structure very similar to a double bottom, and it will also be filled with concrete. Unlike most gravity platforms, ThorConIsle does not include a skirt. Table 1 provides the principal dimensions of the ThorConIsle hull. It is noted that the hull structure has a box shape that gives a block coefficient of unity.

Figure 7 shows the general arrangement of ThorConIsle. Paik (2019a) undertook the structural design and analysis of ThorConIsle's hull structures in association with the North Atlantic sea states in towing and operation. Figure 8 presents the finite-element model of ThocConIsle's hull structures for structural analysis, in which only plate-shell elements were used to model the structural members, i.e., without using simplified beam elements to model support members, where not only plating between stiffeners but also webs or flanges of stiffeners were modeled by plate-shell elements. The total numbers of plate-shell elements and nodal points were 577,685 and 530,580, respectively.

Table 1. Principal dimensions of the ThorConIsle hull.

\begin{tabular}{|l|l|}
\hline Parameter & Dimension \\
\hline Length & $174 \mathrm{~m}$ \\
\hline Breadth & $65 \mathrm{~m}$ \\
\hline Depth & $33 \mathrm{~m}$ \\
\hline Block coefficient & 1.0 \\
\hline
\end{tabular}

The structural analysis (Hughes and Paik 2013, Paik 2018) began with an initial scantling of hull structures and generated optimum design applying the IACS Harmonized Common Structural Rules for Bulk Carriers and Oil Tankers (IACS 2014), which should satisfy the yielding and buckling and/or ultimate strength requirements for both tow and operational conditions. The hull structures were made of mild steel (grade A) and high tensile steel (grade DH36). The maximum hull deflection should also be limited around the turbo generator and other sensitive equipment. Figure 9 presents an example of the structural analysis, with von Mises stress distribution at a wavelength of $174 \mathrm{~m}$, a significant wave height of $9 \mathrm{~m}$, and a phase angle of 90 degrees for a head sea. The buckling and ultimate strength of the structural elements was checked with the MAESTRO program (2019) together with ALPS/ULSAP (2019). 

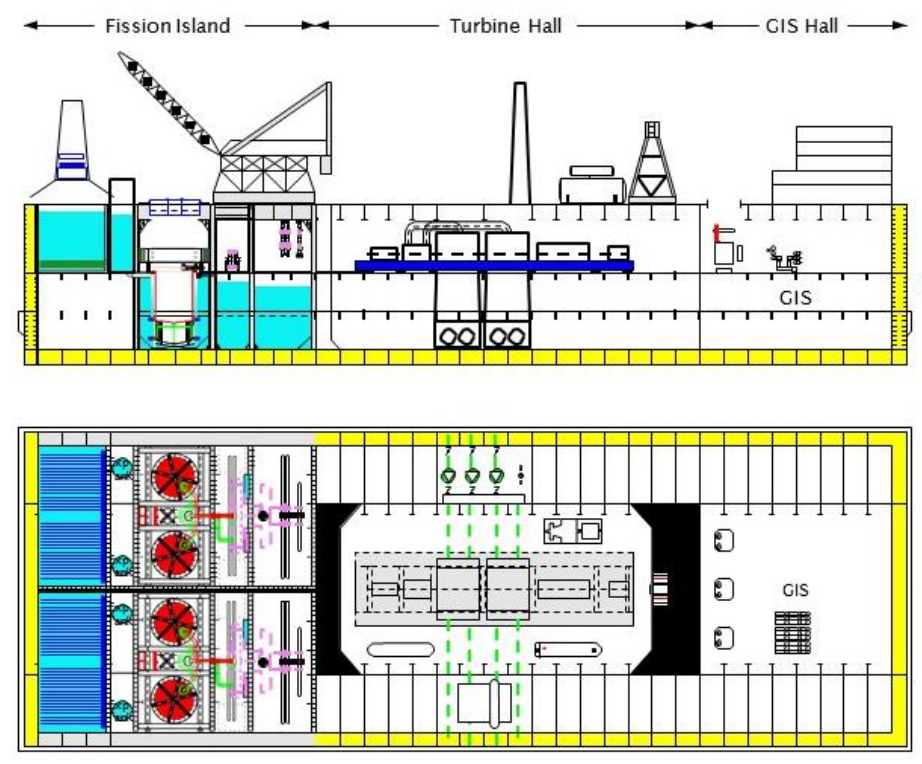

Figure 7. General arrangement of ThorConIsle. (C) ThorCon.

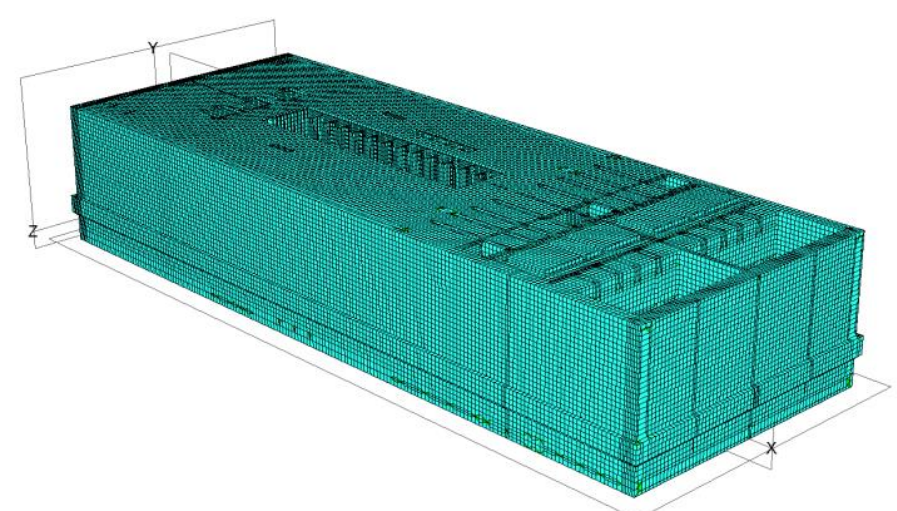

Figure 8. MAESTRO finite-element model of ThorConIsle's hull structures used for structural analysis (Paik 2019a).
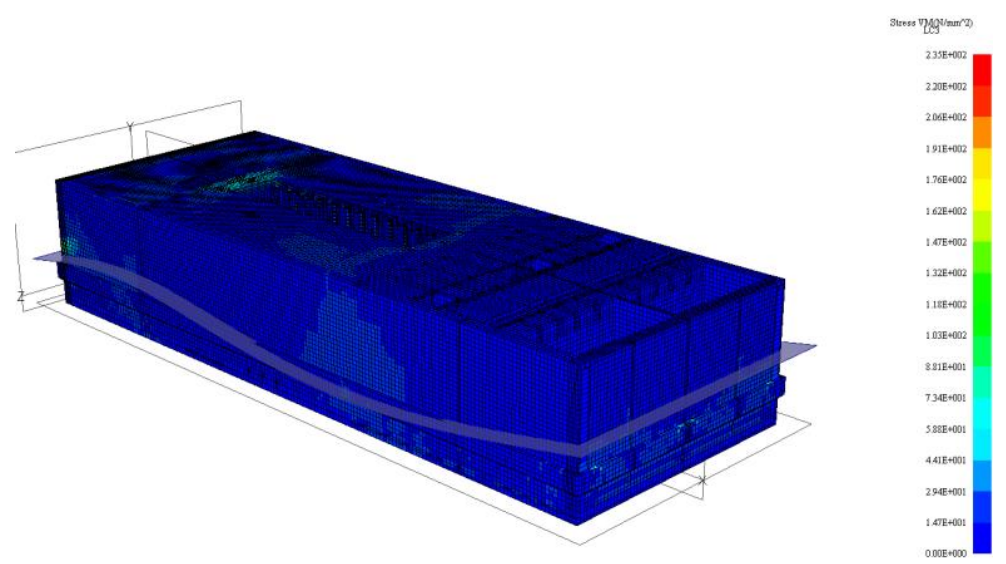

Figure 9. Example of structural analysis for ThorConIsle's hull structures at a given extreme sea state using the MAESTRO program (Paik 2019a). 


\section{Computational Modeling for Structural Crashworthiness Analysis in Aircraft Strike}

The computational modeling for the crashworthiness-based case study of the hull structures described in Section 2 is presented below in the context of an airstrike by a Boeing 777 airplane.

\subsection{Case study plan}

An aircraft strike scenario is considered in which a Boeing 777 airplane operating at full speed collides intentionally with the hull structures in which the silo is located. Figure 10 presents the principal dimensions of a Boeing 777 airplane. Its full speed is considered to be $200 \mathrm{~m} / \mathrm{s}$ (Wierzbicki et al. 2002). Figure 11 shows the collision event between the airplane (the striking body) and the hull structure (the struck body).

The double-side space is filled in with sand or concrete for ballasting, which will contribute to reducing the penetration of the striking body into the hull structures. Therefore, the effects of the two types of ballasting materials (i.e., sand and concrete) are studied in association with the structural crashworthiness. For purposes of comparison, a condition with no ballasting (or in air) is also studied. The LS-DYNA nonlinear finite-element method is used for the structural crashworthiness analysis for an aircraft strike.
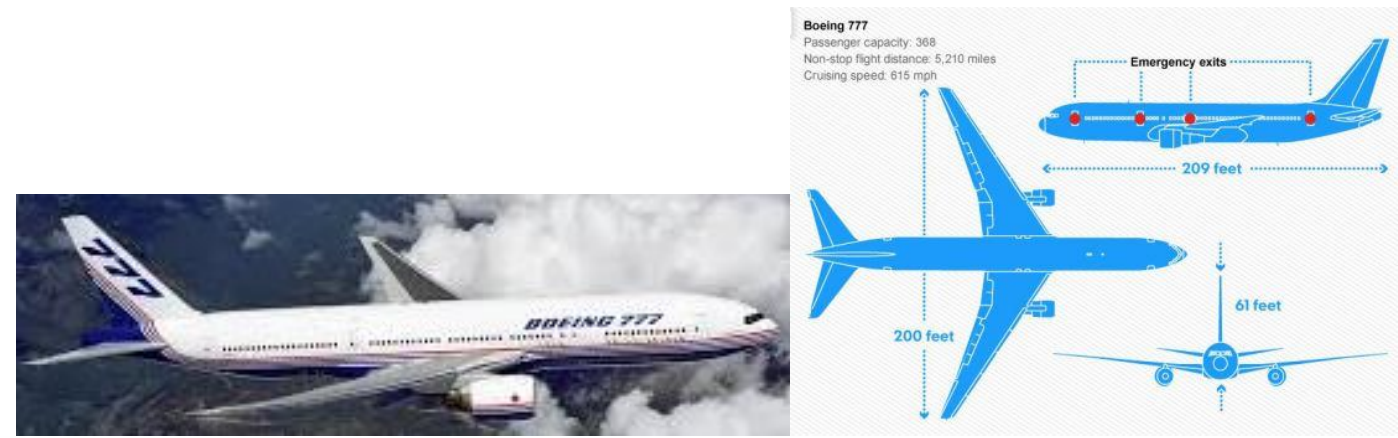

Figure 10. Principal dimensions of a Boeing 777 airplane.

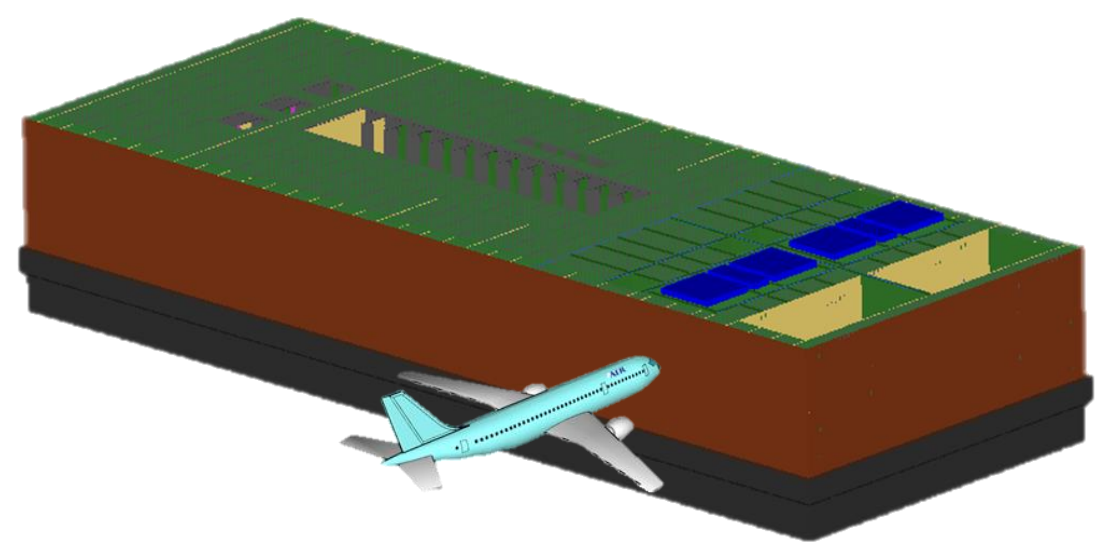

Figure 11. Collision scenario between Boeing 777 airplane and ThorConIsle hull structure. 


\subsection{Structural modeling of striking body}

Airplane bodies are made of very thin shells, and their contribution to the absorption of impact energy is considered to be small. In structural crashworthiness analysis, therefore, it is assumed that only the engine of the airplane, with a mass of 8.282 tons, is contributing. The shape of the engine is simplified as a rectangular parallelepiped body (Figure 12), and the size of the striking body (engine) is $6000 \times 3162 \times 3162$ $\mathrm{mm}$ with a cross-sectional area of $10 \mathrm{~m}^{2}$.

The striking body (engine) was modeled as a deformable body allowing part of the kinetic energy to absorb. Solid elements with fine meshes $(100 \times 100 \times 100 \mathrm{~mm})$ were used at the front part with a length of $3000 \mathrm{~mm}$, whereas slightly coarser meshes $(300 \times 300 \times 300 \mathrm{~mm})$ were used at the rear. The mesh sizes of the deformable body were determined by a convergence study. For a comparison purpose, the structural crashworthiness analysis was also conducted with the striking engine modeled as a rigid body, while exactly the same mesh size as the deformable body was used for a convenience of modeling.

The striking body as a deformable model was considered to be made of mild steel with a yield strength of $235 \mathrm{MPa}$. The same relation of mild steel between true stress versus true strain as for hull structures is employed as later presented in Figure 15. As such, the striking body as a deformable model was modeled by considering the effects of geometric and material nonlinearities, including crushing, fracture, and plasticity (Paik 2018, 2019b). The effect of strain rates was also considered, and the strain rate at the beginning of the impact was about $600 / \mathrm{s}$ according to the LS-DYNA computations. Test database for the effects of strain rates on mechanical properties of mild and high-tensile steel may be referred to in Paik et al. (2017).

Figure 13 presents the effects of the strain rates on the dynamic yield strength and dynamic fracture strain (Paik 2018, 2019b). In this case, the dynamic yield strength is set to $637.2 \mathrm{MPa}$, and the dynamic fracture strain is presumed to be 0.106 as far as the striking body is deformable. For a deformable striking body model, the failure modes of crushing and fracture are allowed as the penetration proceeds. In the LS-DYNA computations, the "Contact-Eroding-Surface-To-Surface" option was used so that new contact surfaces appear as parts of the striking body fail.

In reality, however, the engine of an airplane is mainly a bunch of thin cylinders rather than a rigid body. As observed in the SNL's F4 Phantom test with a full scale airplane (Sugano et al. 1993), where the F4 was a larger, stronger, more concentrated mass than a high bypass turbofan engine, the engine body may be easily crushed instead of continuing the penetration into the hull structure as the striking body may not bounce off and basically intact. In this regard, the engine model used in the present study may give very conservative results in association with the safety of hull structures in an aircraft strike. Further studies are recommended by modeling the engine as a cylinder rather than a box-shaped body. 


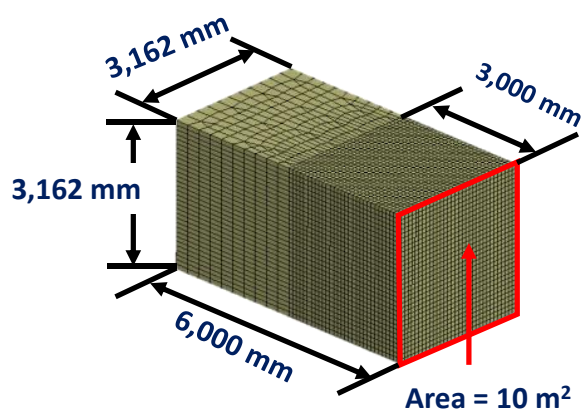

Figure 12. The deformable airplane engine model.

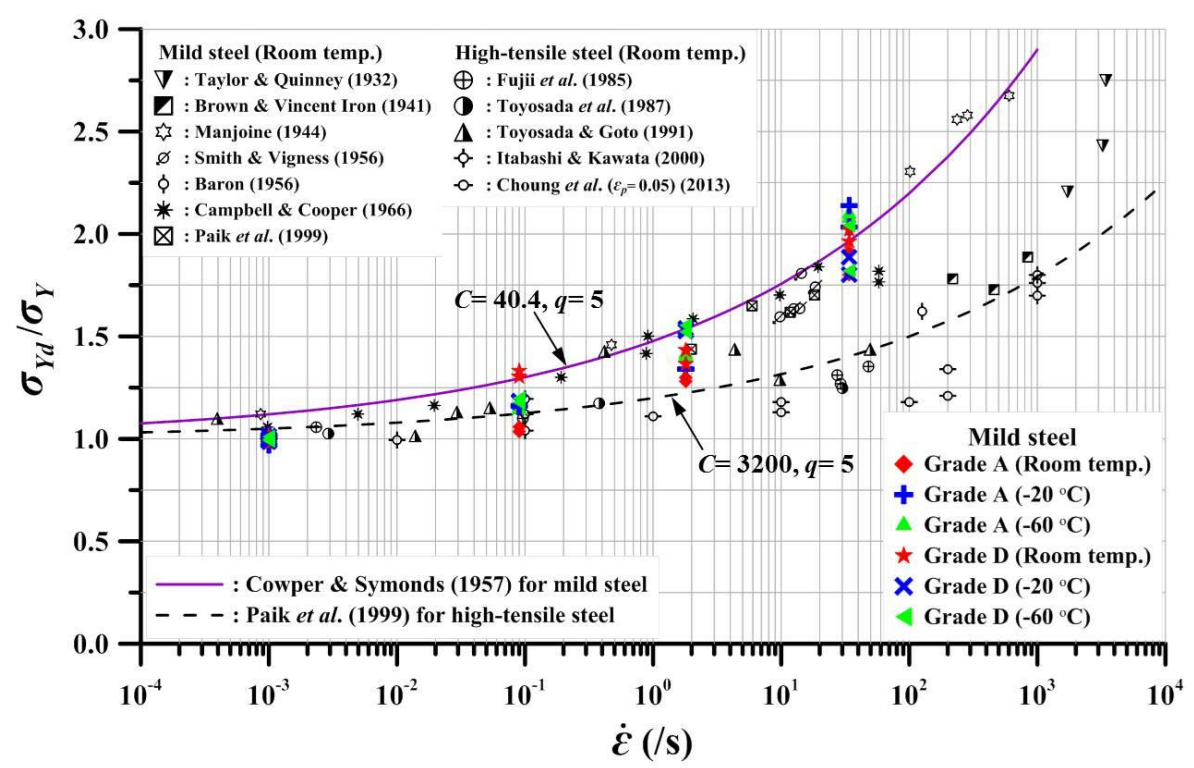

(a) Effects of strain rate on dynamic yield strength of steel.

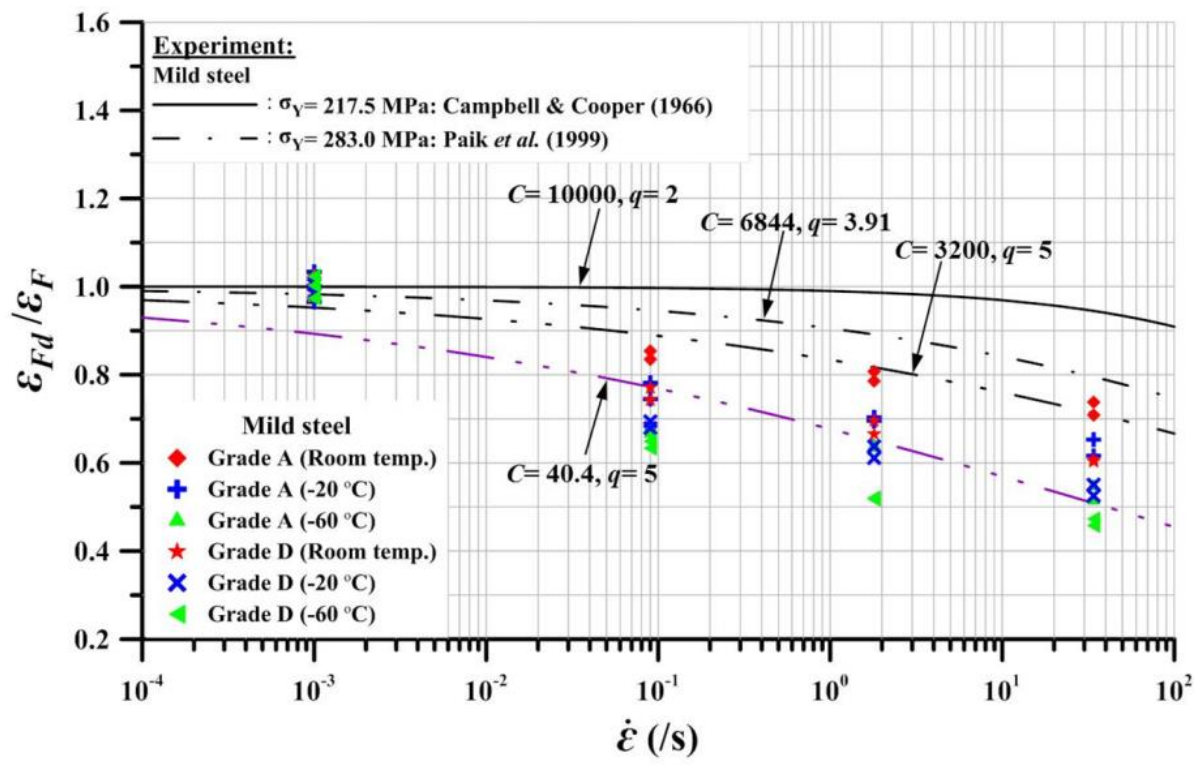

(b) Effects of strain rate on dynamic fracture strain of steel.

Figure 13. Effects of strain rate on dynamic yield strength and the dynamic fracture strain of steel (Paik 2018, 2019b). 


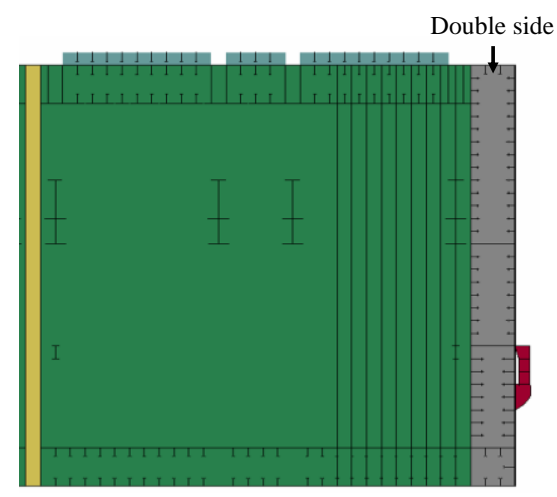

Figure 14. Cross-sectional view of hull structure with double-side space.

\subsection{Structural modeling of ballasting materials}

Sand or concrete is used for ballasting in the double-side space of the ThorConIsle hull in shallow water (Figure 14). It is expected that the ballasting materials contribute to reducing the striking body's penetration because they absorb part of the initial kinetic energy.

Sand was modeled using solid elements with a mesh size of $100 \times 100 \times 100 \mathrm{~mm}$. A lot of uncertainties are still pertinent for modeling soil, but some useful technologies associated with LS-DYNA are available in LS-DYNA (2018) and FHA (2004). The modeling technique in this paper is solely dependent on the guidance of LS-DYNA user's manual. Since the soil on the surface of the ocean is used as a ballasting material, the drained soil that contains water in the soil, was used for this analysis. MAT 147.FHWA_SOIL was used with a mass density of $2350 \mathrm{~kg} / \mathrm{m}^{3}$ in LS-DYNA computations.

Concrete was also modeled using solid elements with a mesh size of $100 \times 100 \times$ $100 \mathrm{~mm}$. Several material cards for concrete are available in LS-DYNA (2018), namely

- MAT 72R3 (*MAT_CONCRETE_DAMAGE_REL3)

- MAT 111 (*MAT_JOHNSON_HOLMQUIST_CONCRETE)

- MAT 159 (*MAT_CSCM_CONCRETE)

MAT 72R3 card models concrete as brittle material, MAT 111 card models concrete as plastic material, and MAT 159 card models concrete as an eroded material. Erosion criteria are formulated based on strain energy of elements as described in detail (LS-DYNA 2018, Fan et al. 2011). It is recognized that with the MAT 72R3 the damage region is maximized by spreading out of the striking location. MAT 111 shows a limited damage around the perforation of striking body. With the MAR 159, the damage is concentrated at the exit of the striking body. This paper adopts the MAT 159 card to model the concrete with a mass density of $2300 \mathrm{~kg} / \mathrm{m}^{3}$ at a pessimistic perspective because penetration of the striking body is maximized to reach the nuclear equipment inside hull structures.

Furthermore, the striking body must be deformable, and the interacting effect between two colliding bodies is complex in many aspects and it should not be overlooked (Ko et al. 2018). The energy absorption characteristics of two colliding 
bodies will depend on individual structural properties, indicating that both the material and geometric properties for two colliding bodies should be realistic. As such, this paper deals with the striking engine as a deformable body which allows deformations to happen and part of the initial kinetic energy can be consumed by failure of the striking engine.

\subsection{Structural modeling of struck body}

Struck hull structures are made of mild steel (MS24) and high tensile steel (DH36). Figure 15 shows the stress-strain relations of materials used for the structural crashworthiness analysis. Table 2 summarizes the material properties used for the analysis. The dynamic yield strength of material was estimated from the Cowper-Symonds equation which is given by

$$
\sigma_{Y d}=\left[1+\left(\frac{\dot{\varepsilon}}{C}\right)^{1 / q}\right] \sigma_{Y}
$$

where $\sigma_{\mathrm{Y}}$ is the yield strength, $\sigma_{\mathrm{Yd}}$ is the material yield strength, $\dot{\varepsilon}$ is the strain rate, and $\mathrm{C}$ and $\mathrm{q}$ are the Cowper-Symonds coefficients which are taken as $\mathrm{C}=40.4$ and $\mathrm{q}=5$ for mild steel and $\mathrm{C}=3200$ and $\mathrm{q}=5$ for high tensile steel (Paik 2018).

Unlike for the ultimate strength analysis where an elastic-perfectly plastic material model is usually employed in association with engineering stress-engineering strain relation without considering the strain-hardening effect, the structural crashworthiness analysis involving crushing and rupture needs to use the true stress-true strain relation with considering the effects of strain hardening and necking as large plastic strains may happen (Paik 2019b). The dynamic yield strength and the dynamic fracture strain are affected by the strain rate effects in association with a maximum strain rate of 600 /s (Paik 2018, 2019b). The values used for the dynamic yield strength and the dynamic fracture strain for mild steel are the same as those used for the striking body. For high tensile steel, the dynamic yield strength is $608.4 \mathrm{MPa}$, and the dynamic fracture strain is 0.125 .

The conventional approach of nonlinear finite element method was used to model the struck hull structures. The analysis included a length of $30 \mathrm{~m}$, a width of $32 \mathrm{~m}$, and a depth of $33 \mathrm{~m}$ in the range of 126 to $156 \mathrm{~m}$ of the hull where the silo is located (Figure 16). The hull structure (struck body) was modeled using rectangular-type plate-shell elements. The mesh size around the collision site (17 $\mathrm{m}$ long and $8 \mathrm{~m}$ wide) was $100 \times 100 \mathrm{~mm}$, which was determined in a convergence study (Figure 17). Figure 18 shows the complete model of the collision analysis in which the fine mesh zone extends to $8000 \mathrm{~mm}$ from the outer side shell. The mesh size far from the collision area is much larger, in which one plate-shell element is used between stiffeners, in a stiffener web, or in a stiffener flange. 


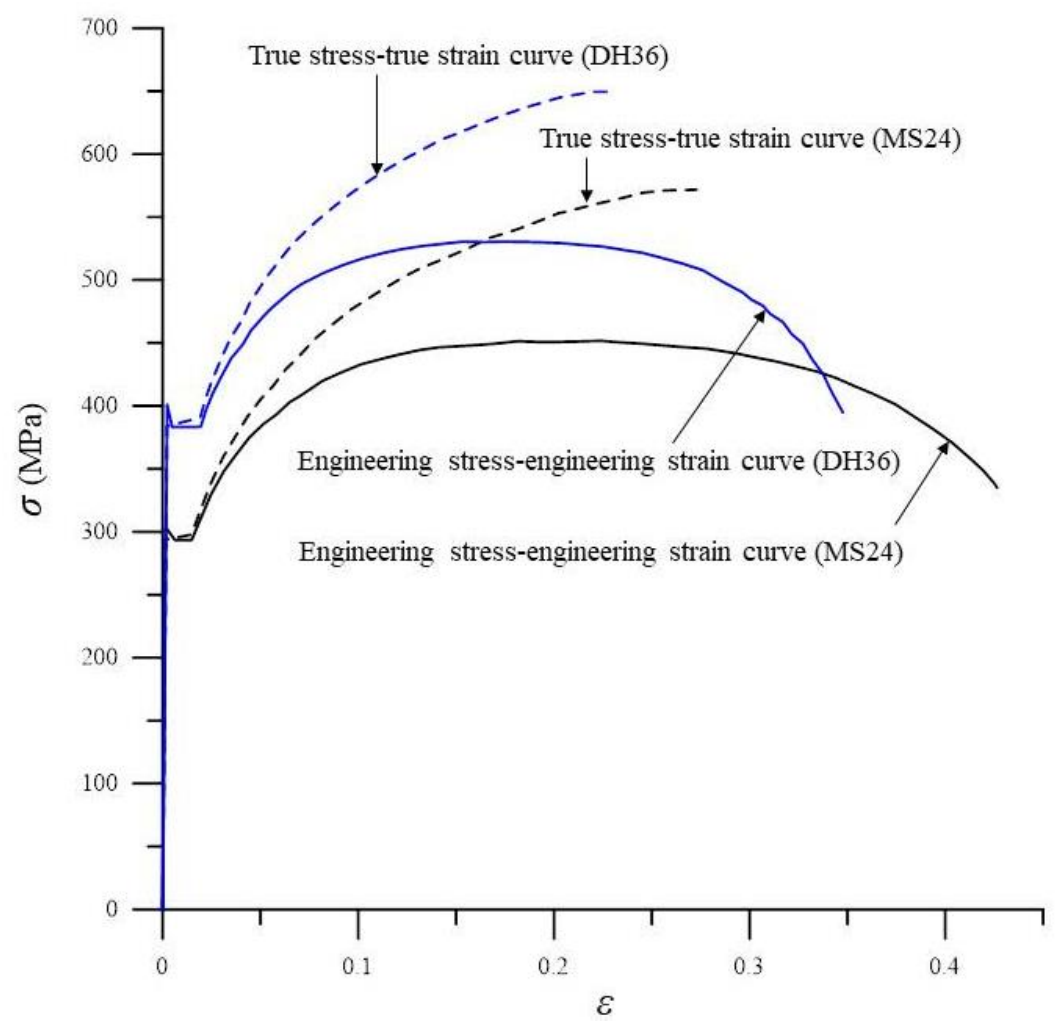

Figure 15. Stress-strain relations of mild and high tensile steels used for the crashworthiness analysis of hull structures at zero strain rate.

Table 2. Material properties used for the crashworthiness analysis of hull structures.

\begin{tabular}{|l|l|l|}
\hline Material property & Mild steel (MS24) & High tensile steel (DH36) \\
\hline Density, $\rho$ (ton/m3) & 7.85 & 7.85 \\
\hline Young's modulus, $E(\mathrm{MPa})$ & 205,800 & 205,800 \\
\hline Poisson's ratio, $v$ & 0.3 & 0.3 \\
\hline Yield stress, $\sigma_{Y}(\mathrm{MPa})$ & 235 & 355 \\
\hline $\begin{array}{l}\text { Cowper-Symonds } \\
\text { Coefficient }\end{array}$ & $\mathrm{C}=40.4$ & $\mathrm{C}=3200$ \\
\cline { 2 - 3 } & $\mathrm{q}=5$ & $\mathrm{q}=5$ \\
\hline
\end{tabular}




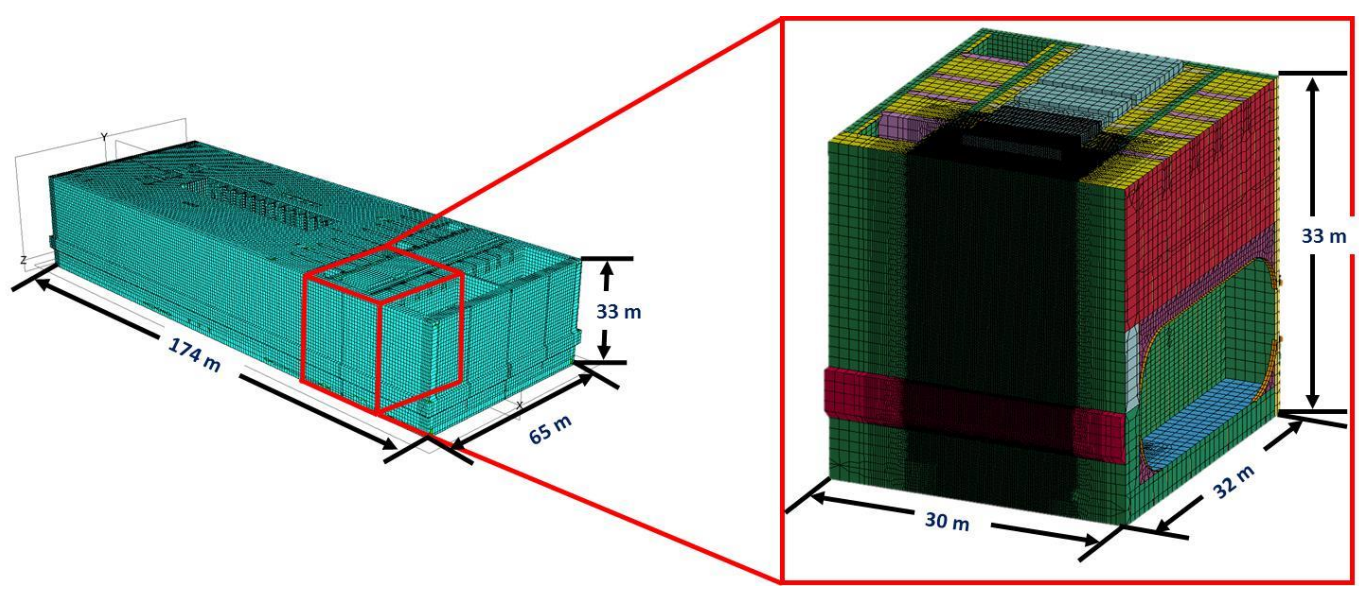

Figure 16. Extent of the analysis in the hull structure.

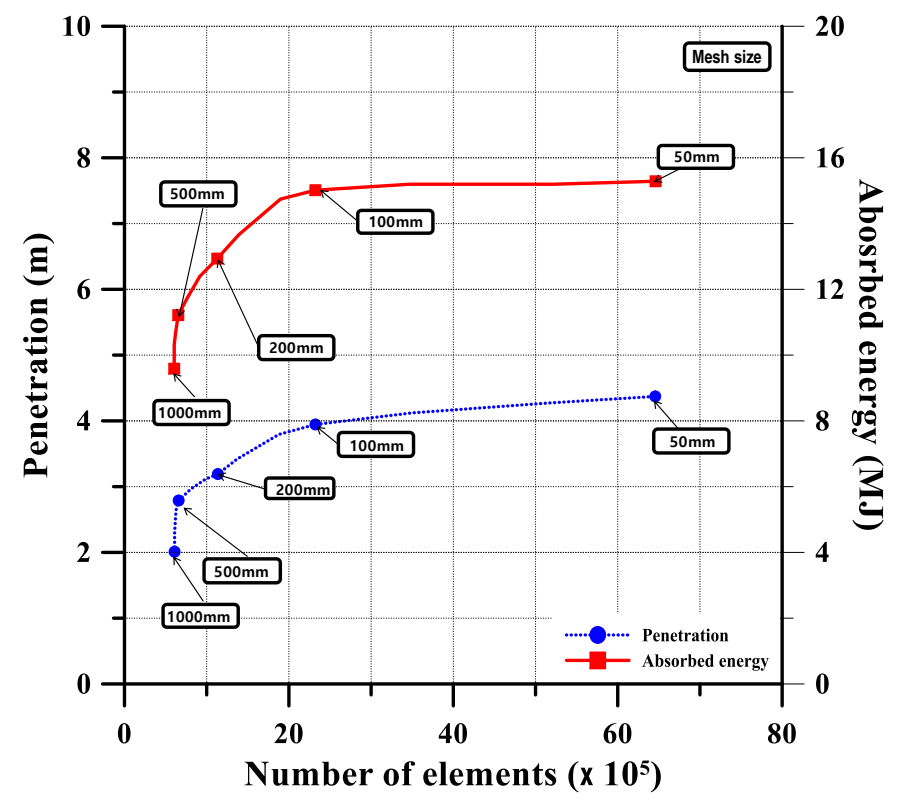

Figure 17. Convergence study to determine best mesh size.

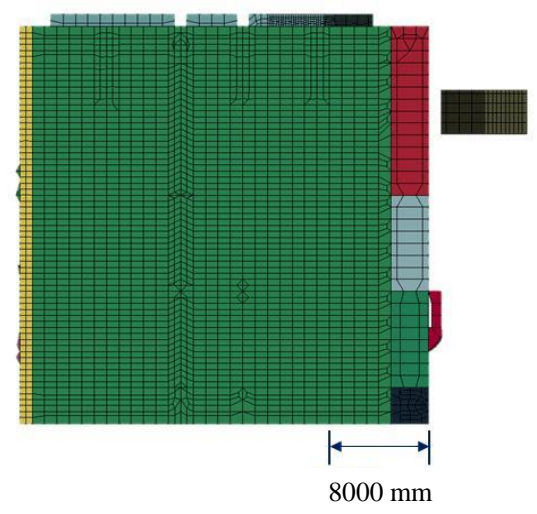

Figure 18. Complete model of airplane strike scenario for structural crashworthiness analysis. 


\section{Computational Results and Discussion}

Attention is paid to the safety of the silo located $4500 \mathrm{~mm}$ inside the outer hull with a double-side width of $3000 \mathrm{~mm}$ as shown in Figure 19. A comparison of the resultant force and the absorbed energy responses of the hull structures over time is shown in Figure 20 between no ballast, sand ballast, and concrete ballast when a deformable striking body model is applied.

In Figure 20(a), the results of the F4 Phantom test are also compared. The size of the F4 Phantom is very small compared to the Boeing 777 airplane, as shown in Figure 21, but the mass of the engine is comparable. It is found that the resultant forces obtained from the F4 Phantom test are much smaller than those from the present simulations. By combining both the resultant force-time relationship and the penetration-time relationship, the resultant force-penetration relationship can be obtained together with the relationship between the kinetic energy (absorbed by hull structures) versus penetration, as shown in Figure 22. It is noted that the "penetration" indicated in Figure 22 was measured with respect to the tip of the striking engine, and it is not equal to the indented distance from the outer hull toward the silo as shown in Figure 19.

In concrete ballasting material as shown in Figure 22(c), the relationship between force and penetration is linear in the beginning and the resulting amount of the initial kinetic energy absorbed by hull structures is very small. This may be due to the fact that the deformable striking body mainly contributes to the energy absorption until the failure of concrete starts.

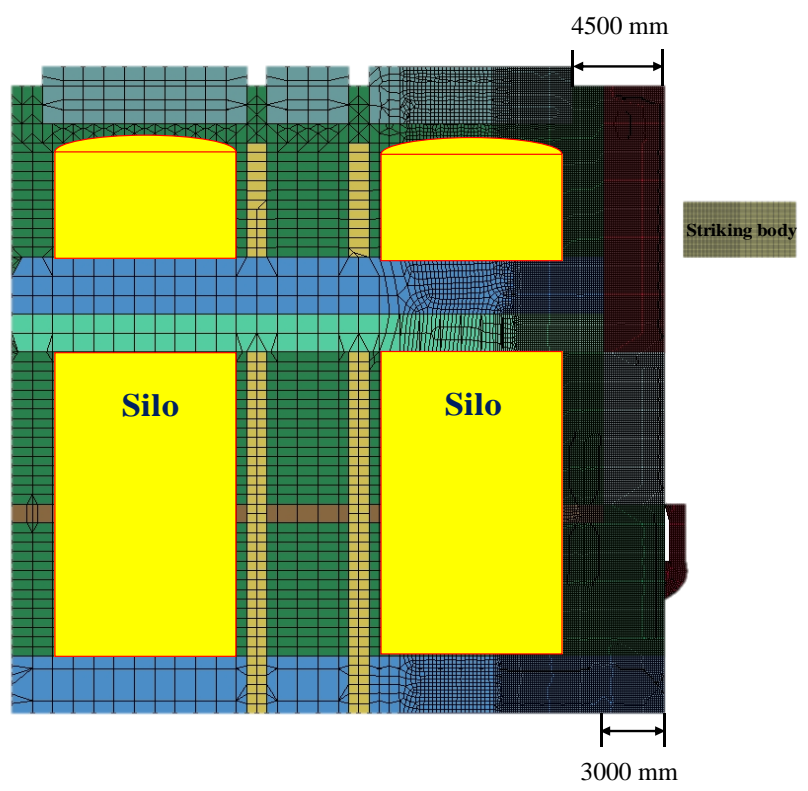

Figure 19. Location of silo. 


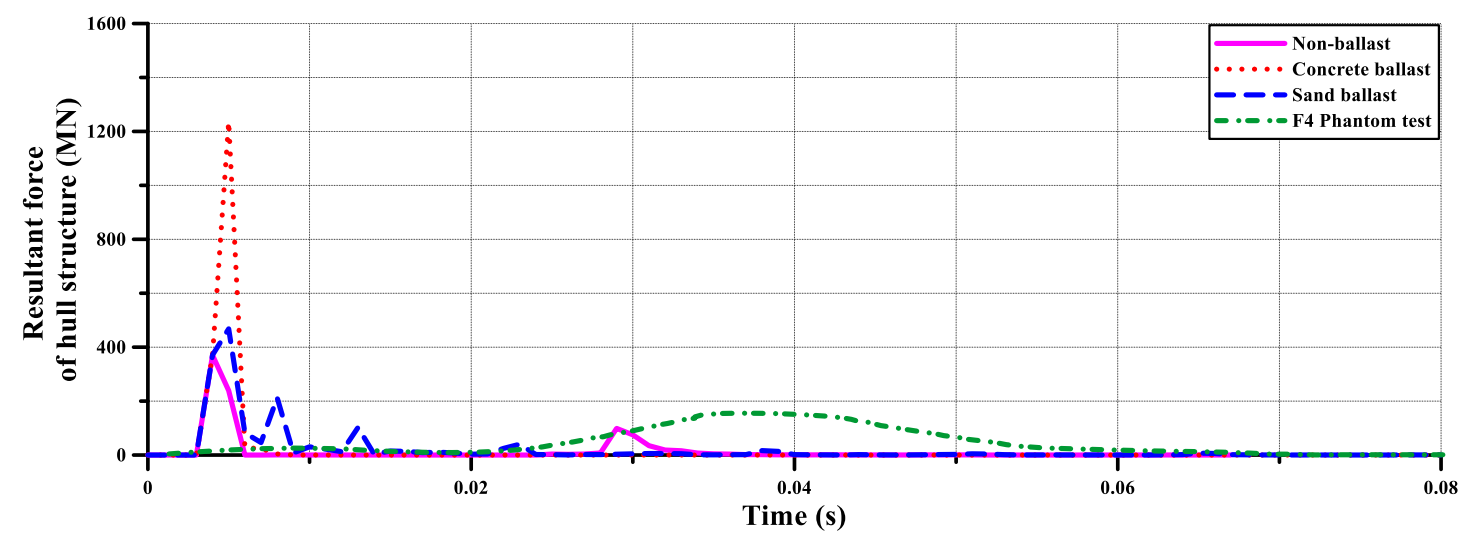

(a) Resultant force-time relationship.

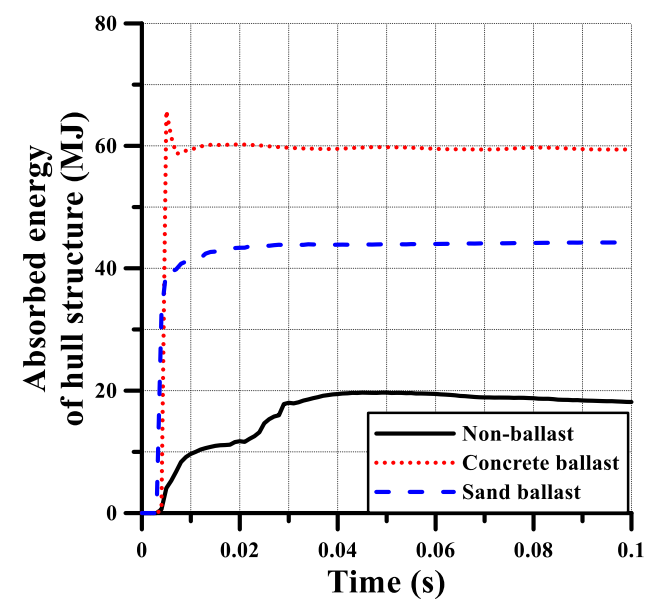

(b) Absorbed energy-time relationship.

Figure 20. Comparison of the resultant force-time relationship and the absorbed energy-time relationship between no ballast, sand ballast, and concrete ballast conditions with a deformable striking engine.

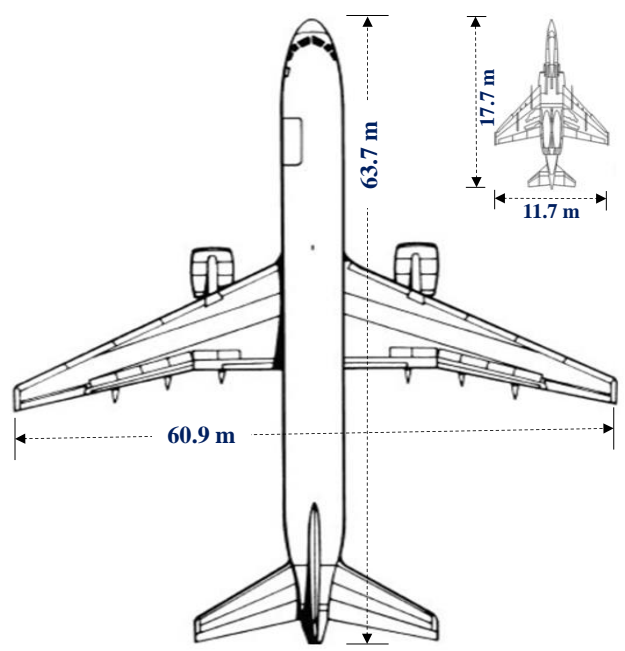

Figure 21. Comparison of the body size between a F4 Phantom and a Boeing 777 airplane. 

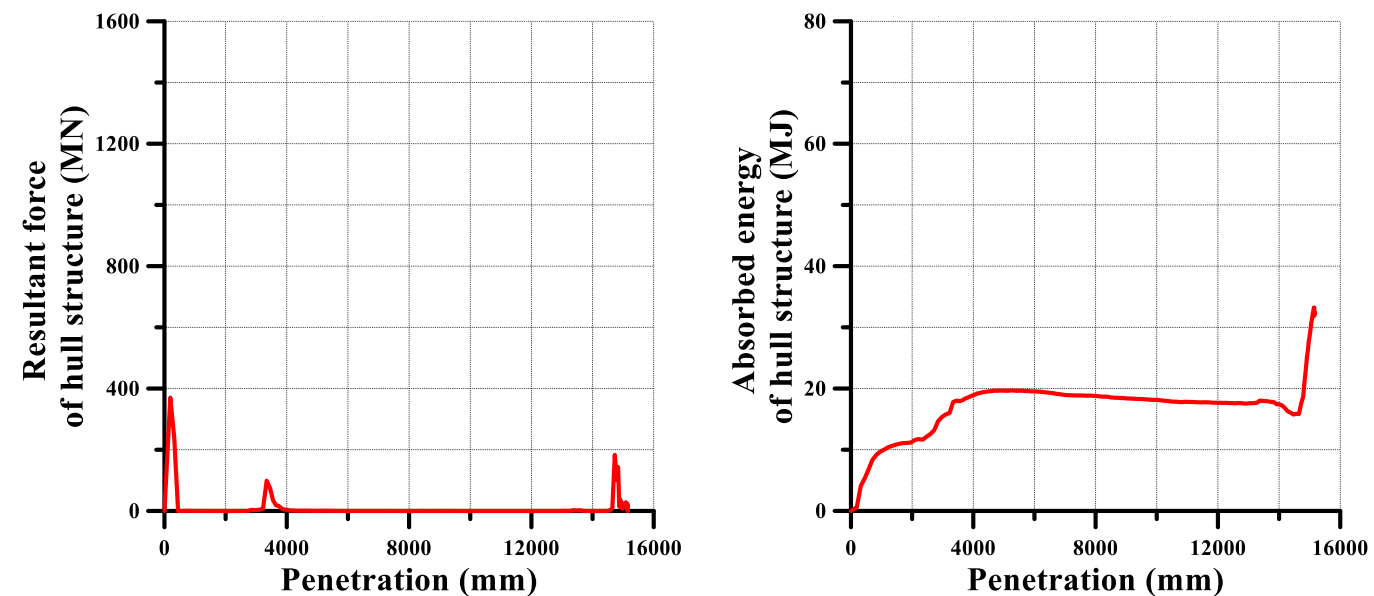

(a) No-ballast condition.
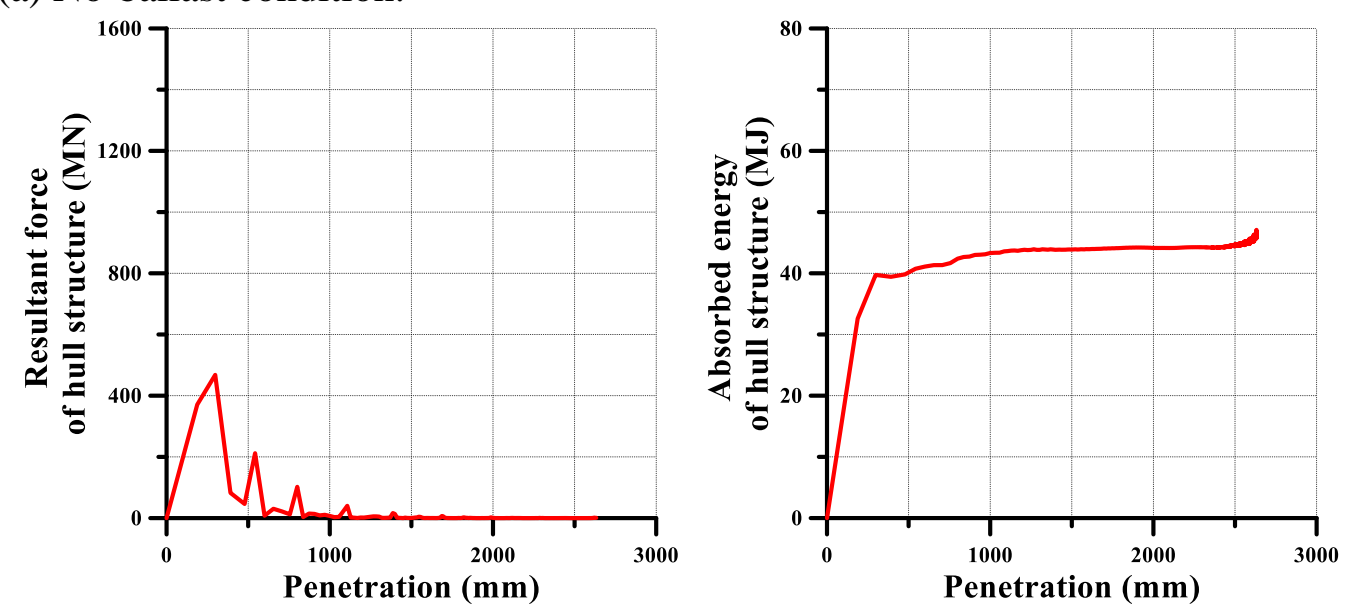

(b) Sand ballast condition.
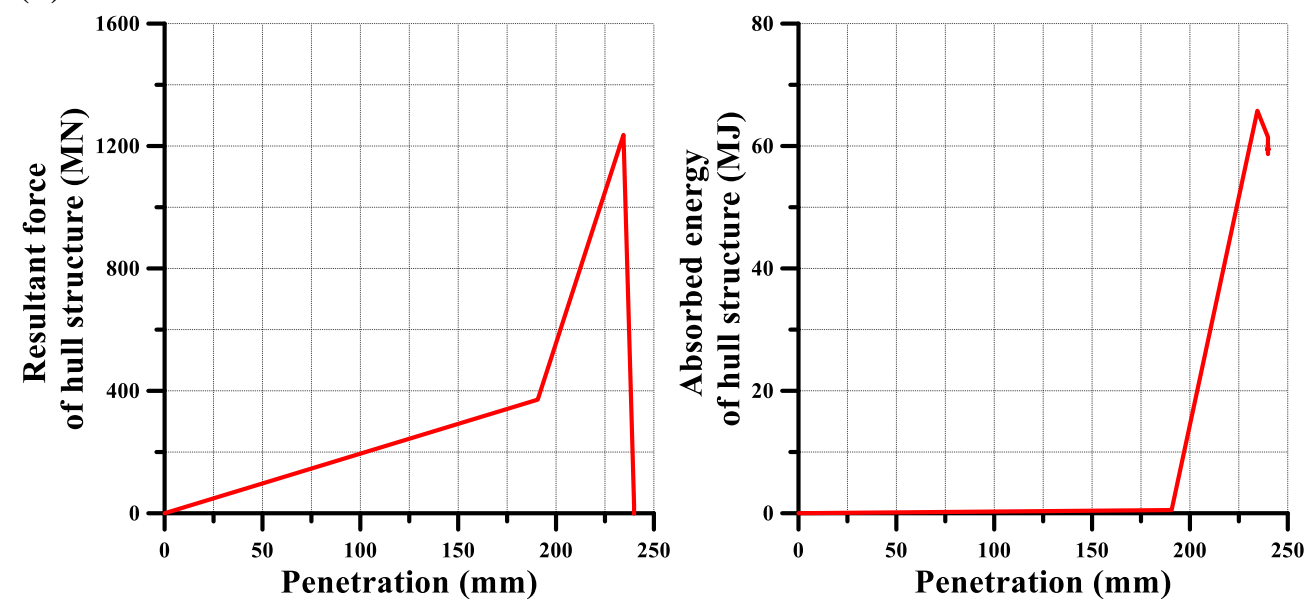

(c) Concrete ballast condition.

Figure 22. Relationship of resultant force or kinetic energy absorbed by hull structures in association with penetration with a deformable striking engine.

Figure 23 presents the deformation and failure status of the hull structures with no ballast, sand ballast, and concrete ballast with the application of a deformable striking body model. During the collision, the inner side shell can deform or deflect toward the silo when ballast materials are filled in, as shown in Figures 24(b) and (c), although the striking body passes through the double-sided structures in the no-ballast 
condition, as shown in Figure 24(a). It is observed that the maximum deformation of the inner side shell is greater in the concrete ballast condition than in the sand ballast condition, as shown in Figure 25, but it is low enough to secure the safety of the silo without any damage.

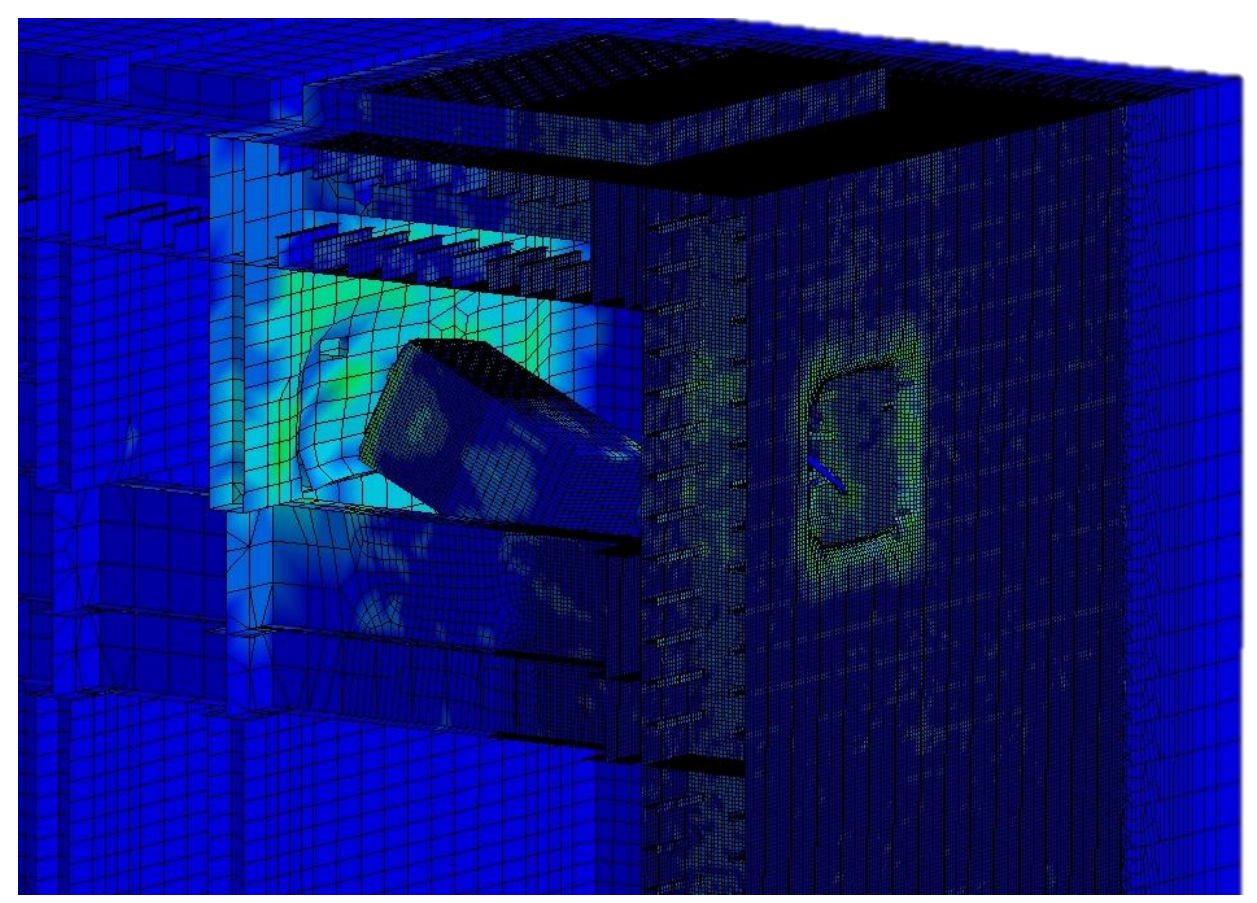

(a) No-ballast condition.

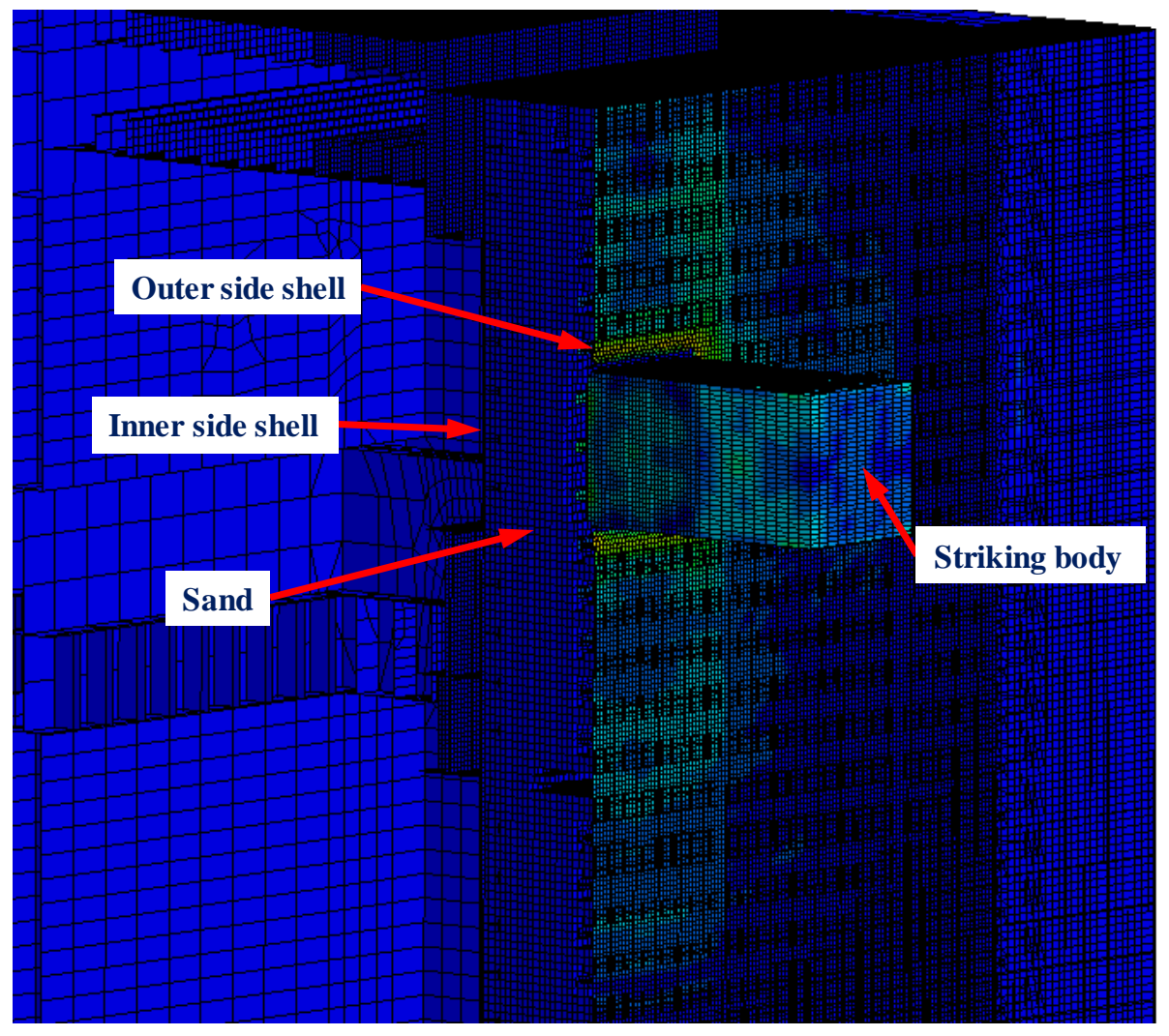

(b) Sand ballast condition. 


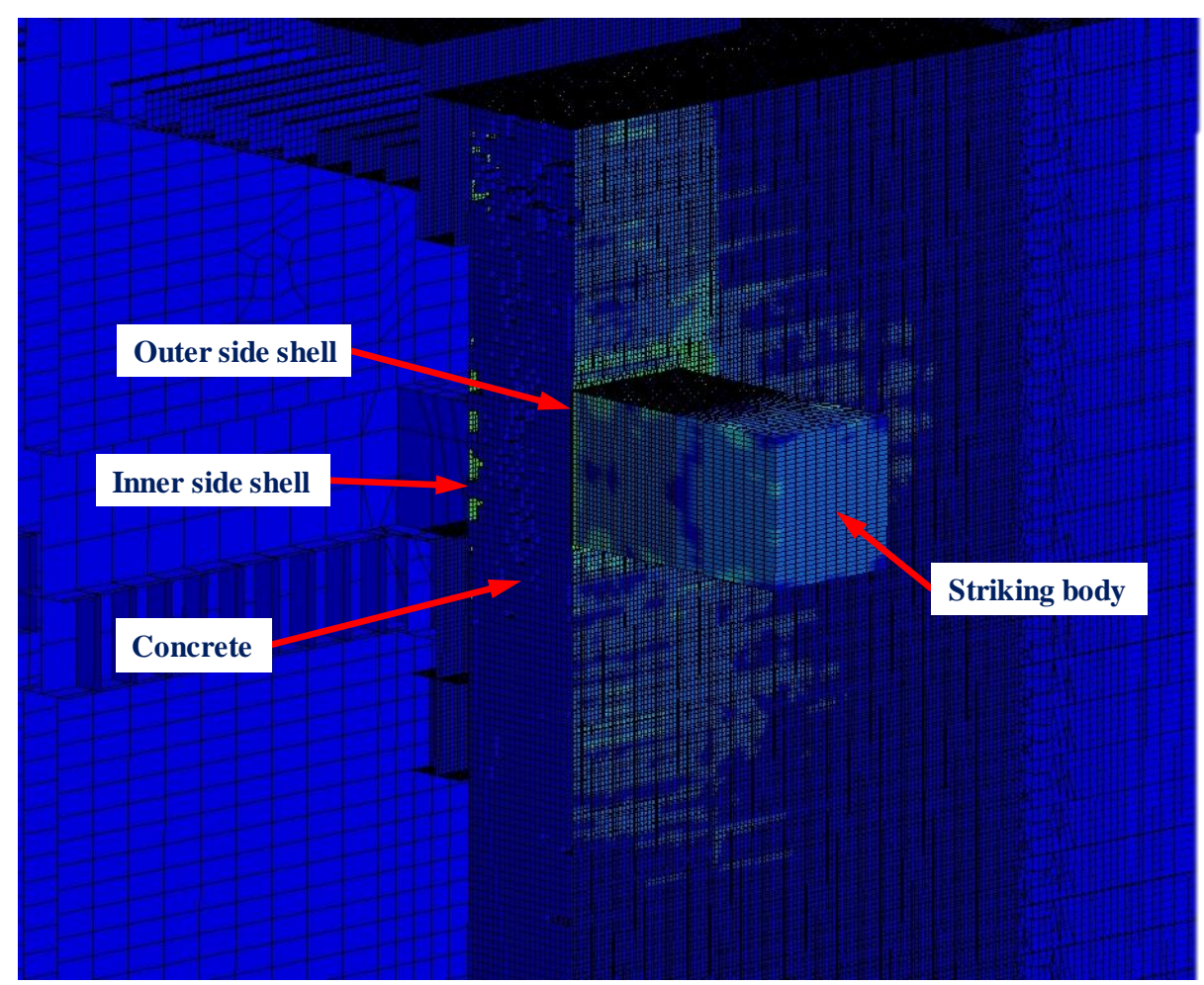

(c) Concrete ballast condition.

Figure 23. Damage and failure status of hull structures with a deformable striking body.

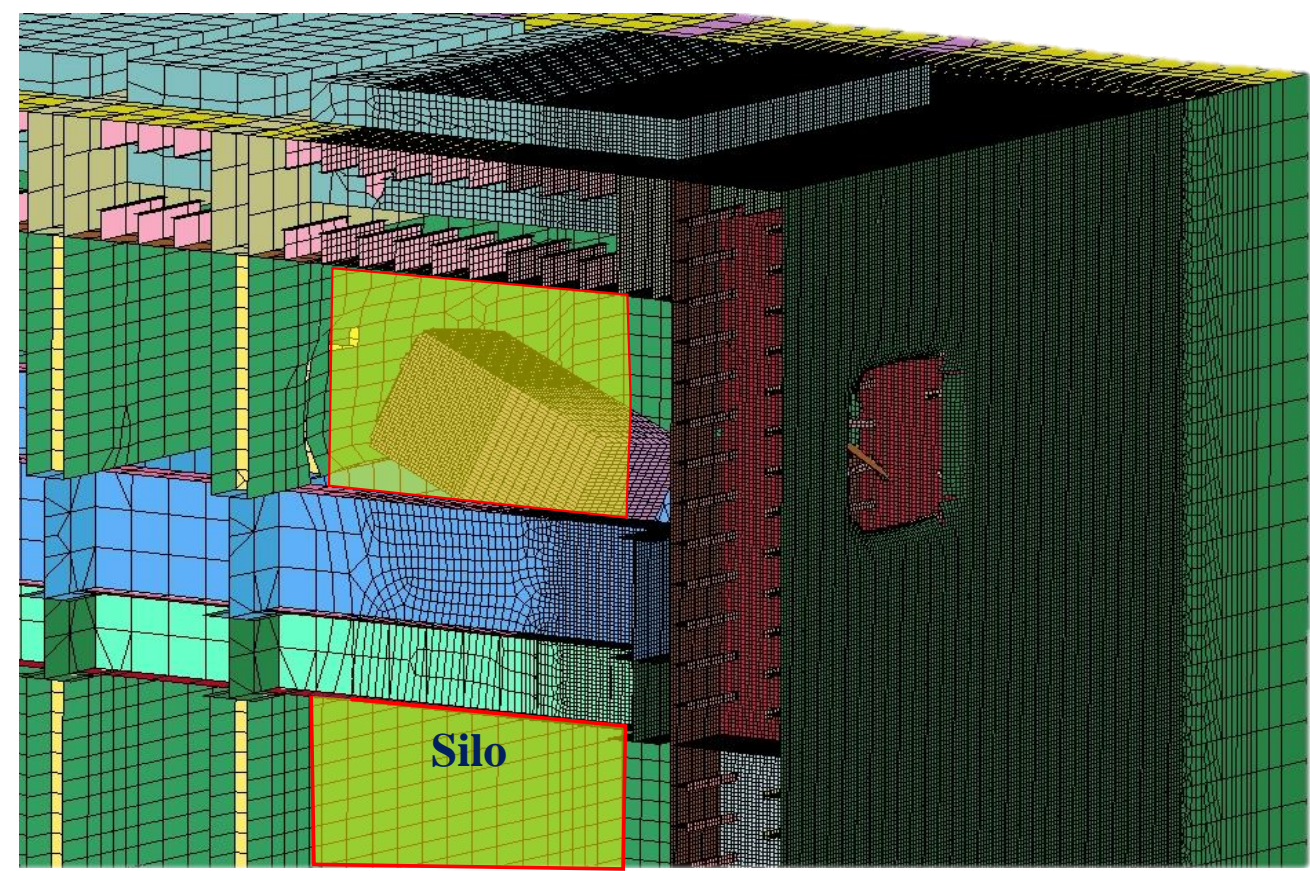

(a) No-ballast condition. 


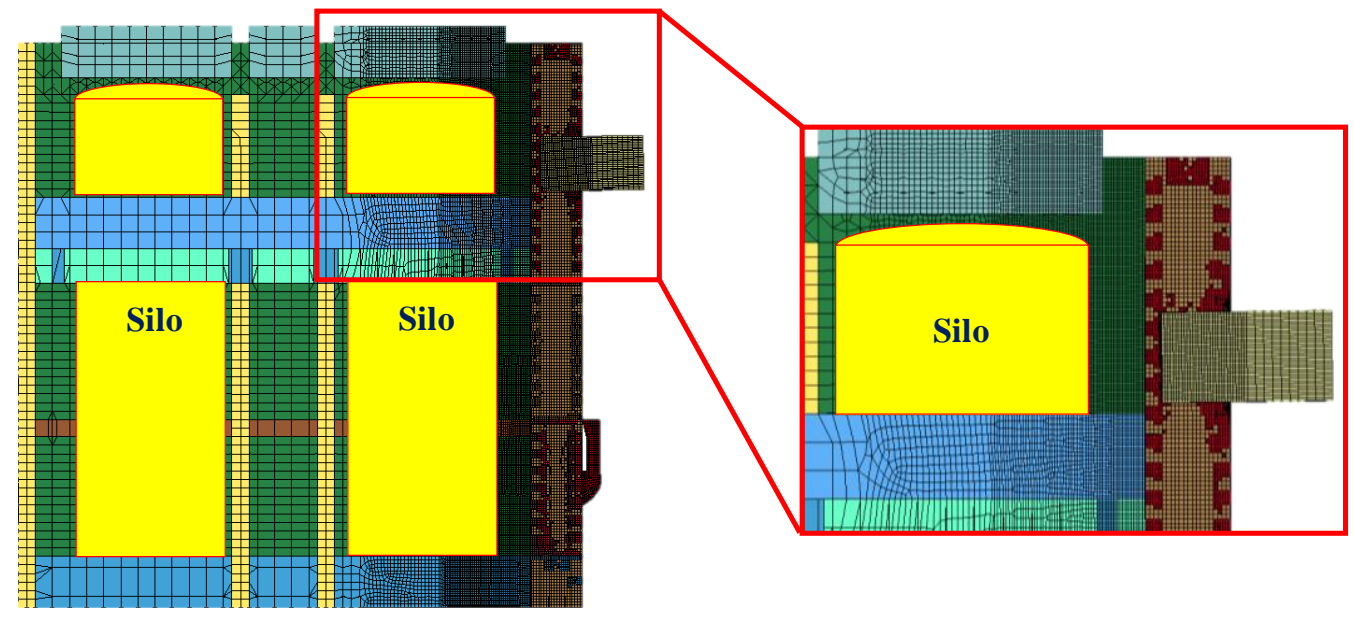

(b) Sand ballast condition.

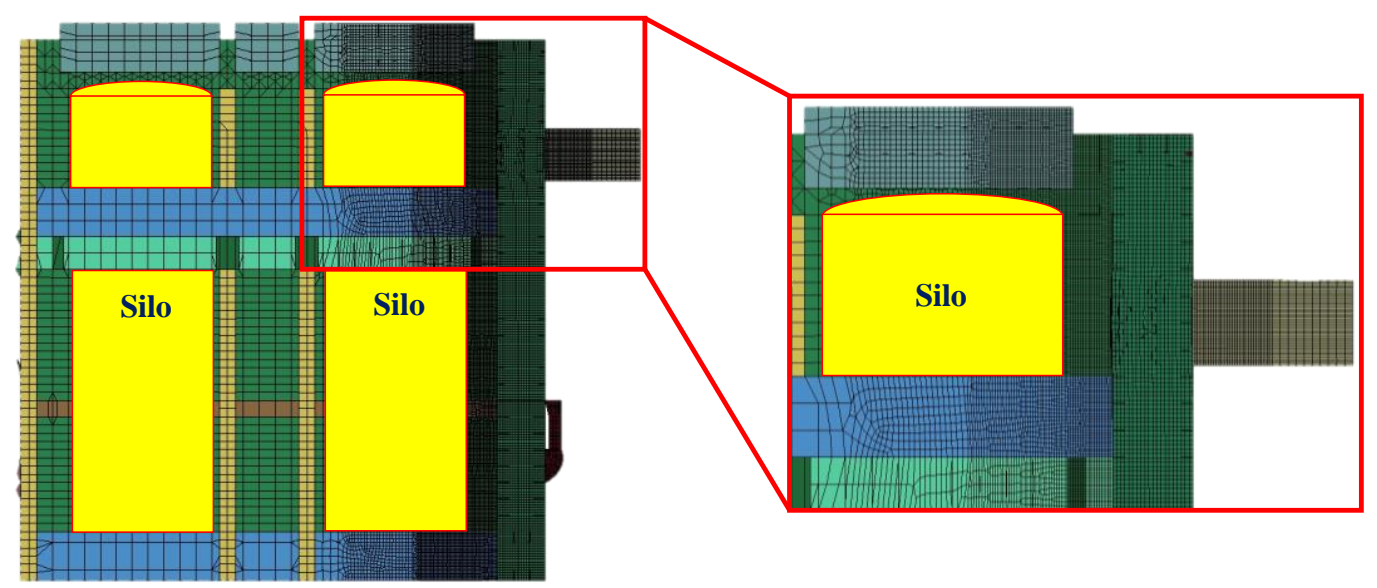

(c) Concrete ballast condition.

Figure 24. Deformation pattern of inner side shell with a deformable striking body. 


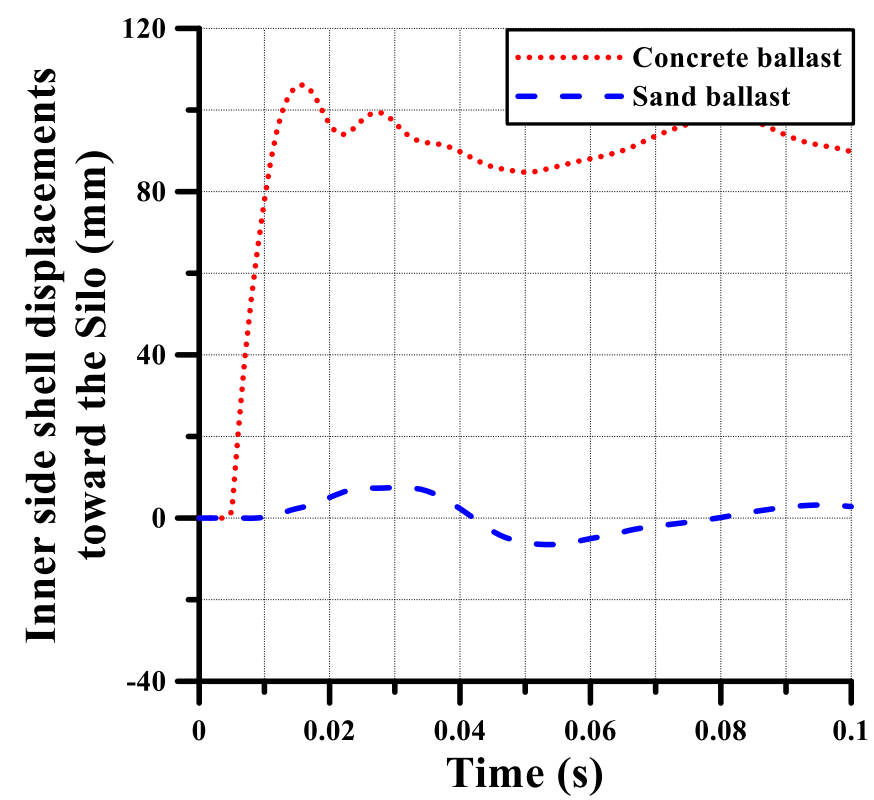

Figure 25. Maximum deflection of inner side shell toward the silo with a deformable striking body.

For a comparison purpose, similar computations were conducted with the application of a rigid striking body model. The rigid striking body does not absorb the initial kinetic energy, so the resulting deformation is greater than with a deformable striking body as indicated in Table 3, where the effects of a rigid striking body model were found to be small for these specific case studies. As no fracture occurred in the inner side shells when sand or concrete ballast materials were used, it was confirmed that the silo was secured at the airplane strike scenario even with the striking engine modeled as a rigid body.

Table 3. Maximum "penetration" at the tip of the striking engine and maximum deflection of inner side shell.

\begin{tabular}{|c|l|l|l|}
\hline $\begin{array}{c}\text { Striking } \\
\text { body model }\end{array}$ & Ballast condition & $\begin{array}{l}\text { Maximum penetration } \\
\text { of the striking body } \\
(\mathrm{mm})\end{array}$ & $\begin{array}{l}\text { Maximum deflection of } \\
\text { inner side shell }(\mathrm{mm})\end{array}$ \\
\hline \multirow{3}{*}{ Rigid } & No ballast & 15,610 & Pass-through \\
\cline { 2 - 4 } & Sand ballast & 2,707 & 9 \\
\cline { 2 - 4 } & Concrete ballast & 250 & 110 \\
\hline \multirow{3}{*}{ Deformable } & No ballast & 15,150 & Pass-through \\
\cline { 2 - 5 } & Sand ballast & 2,639 & 8 \\
\cline { 2 - 5 } & Concrete ballast & 240 & 106 \\
\hline
\end{tabular}




\section{Concluding Remarks}

The aim of this study was to investigate the effects of ballasting materials on the safety of a floating nuclear power plant hull structure in an aircraft strike scenario. Conventional methods were used for the structural crashworthiness analysis using the LS-DYNA nonlinear finite-element method. Based on the study, the following conclusions can be drawn together with the recommendations of further studies.

(1) Both the striking body (engine) and the struck body (hull) were modeled as a deformable body by taking into account their interacting effects, which allowed to absorb part of the initial kinetic energy during collision.

(2) For a comparison purpose, the structural crashworthiness analysis with the striking engine modeled as a rigid body was also conducted. Penetration with the rigid striking body is greater than that with the deformable striking body.

(3) The use of ballasting materials such as sand or concrete in the double-side space of the hull structure can effectively absorb the initial kinetic energy in an aircraft strike.

(4) With both sand and concrete ballasting materials, the safety of nuclear equipment (e.g., silo) inside hull structures was considered to be secured against the terrorist attack with the aircraft strike scenario as the maximum penetration did not reach the equipment with the striking engine modeled by either the deformable or rigid body.

(5) Sand ballasting material is easier to handle to fill in the double-side space than concrete. As far as the safety criteria against aircraft strike are secured, sand ballasting material will be a more useful option.

(6) The striking body (engine) has been modeled as a rectangular-shaped solid body. However, the engine of an airplane is mainly a bunch of thin cylinders which will almost certainly turn to dust on impact as observed in the SNL's F4 Phantom test with a full scale airplane where the F4 was a larger, stronger, more concentrated mass than a high bypass turbofan engine. In this case, the engine may not bounce off and basically intact, and subsequently the engine model used in the present study may give pessimistic results. As such, further studies are recommended by modeling the engine as a cylinder (rather than a solid body) with more realistic properties of materials.

(7) Further studies are recommended for large-scale physical model testing with ballasting materials such as sand or concrete. In addition, all airplane body structures, including the engine, should be included in the structural model to obtain more realistic responses of impact crashworthiness in association with the interacting effects between the striking and struck bodies. It would also be interesting to investigate the effects of water ballasting as far as a vacuum condition (watertight) is secured in the double-side space of the hull structure. 


\section{Acknowledgments}

This study was undertaken at the International Centre for Advanced Safety Studies (www.icass.center) / the Korea Ship and Offshore Research Institute at Pusan National University, which has been a Lloyd's Register Foundation Research Centre of Excellence since 2008. The authors are grateful to the ThorCon International (www.thorconpower.com) which allowed for presenting the results of the study to the public.

Jeom Kee Paik: ORCID 0000-0003-2956-9359

\section{References}

Adams R (1995). Army nuclear power plants. Atomic Insights, November.

ALPS/ULSAP (2019). A computer program for the ultimate strength analysis of plates and stiffened panels. MAESTRO Marine LLC, Greensboro, MD, USA (www.maestromarine.com).

Fan J, Zhang J, Chen H, Jin Z (2011). Advances in heterogeneous material mechanics. Proceedings of the Third International Conference on Heterogeneous Material Mechanics, 22-26 May 2011, Shanghai, China.

FHA (2004). Manual for LS-DYNA soil material model 147. Report No. FHWA-HRT-04-095, Turner-Fairbank Research Center, Federal Highway Administration, McLean, VA, USA.

Foro Nuclear (2019). What is a floating nuclear power plant? Madrid, Spain.

Hughes OF and Paik JK (2013). Ship structural analysis and design. The Society of Naval Architects and Marine Engineers, Alexandria, VA, USA.

IACS (2014). Harmonized common structural rules for bulk carriers and oil tankers. London, UK.

Itoh M, Katayama M, Rainsberger R (2005). Computer simulation of an F-4 Phantom crashing into a reinforced concrete wall. WIT Transactions on Modelling and Simulations, WIT Press, 40: 207-217.

Ko YG, Kim SJ, Paik JK (2018). Effects of a deformable striking ship's bow on the structural crashworthiness in ship-ship collisions. Ships and Offshore Structures, 13: 228-250.

LS-DYNA (2018). User's Manual (version 971). Livermore Software Technology Corp., Livermore, CA.

MAESTRO (2019). Version 11.7.0. MAESTRO Marine LLC, Greensboro, MD, USA, http://www.maestromarine.com.

Michael F. Trentacoste (2004). Evaluation of LS-DYNA Soil Material Model 147. U.S. Department of Transportation Federal Highway Administration, Washington, United States.

Paik JK (2018). Ultimate limit state analysis and design of plated structures. $2^{\text {nd }}$ Edition, John Wiley \& Sons, Chichester, UK.

Paik JK (2019a). Structural analysis of the ThorConIsle hull. Department of Mechanical Engineering, University College London, UK.

Paik JK (2019b). Advanced structural safety studies with extreme conditions and 
accidents. Springer, Singapore.

Paik JK, Kim KJ, Lee JH, Jung BG, Kim SJ (2017). Test database of the mechanical properties of mild, high-tensile and stainless steel and aluminum alloy associated with cold temperatures and strain rates. Ships and Offshore Structures, 12(Sup1): S230-S256.

Sugano T, Tsubota H, Kasai Y, Koshika N, Orui S, von Riesemann WA, Bickel DC, Parks MB (1993). Full-scale aircraft impact test for evaluation of impact force. Nuclear Engineering and Design, 140: 373-385.

ThorCon (2019). Design of ThorConIsle (www.thorconpower.com). Stevenson, WA, USA.

Wierzbicki T, Teng X (2003). How the airplane wing cut through the exterior columns of the World Trade Center. International Journal of Impact Engineering, 28(6): 601-625.

Wierzbicki T, Xue L, Hendry-Brogan M (2002). Chapter 4 Aircraft impact damage. In: World Trade Center Building Performance Study: Data Collection, Preliminary Observations, and Recommendations, FEMA 403 Report, The Federal Emergency Management Agency (FEMA) and American Society of Civil Engineers (ASCE), USA, May. 